\title{
Using a cohesive zone modeling to predict the compressive and tensile behavior on the failure load of single lap bonded joint
}

\author{
Benamar Badr \\ Faculty of Technology, University Djillali Liabes, Sidi bel Abbes, Algeria. \\ a_badroo@yahoo.fr \\ Mokhtari Mohamed \\ Laboratoire RTFM, Ecole Nationale Polytechnique Maurice Audin, Oran, Algeria. \\ mokhtarimohamed44@yahoo.fr \\ Madani Kouider \\ Laboratoire LMPM, University Djillali Liabes, Sidi bel Abbes, Algeria. \\ koumad10@yahoo.fr \\ Benzaama Habib \\ Laboratoire LABAB, Ecole Nationale Polytechnique Maurice Audin, Oran, Algeria. \\ habenza@yahoo.fr
}

\begin{abstract}
The aim of this work is to analyze the failure behavior of a simple lap joint of type metal / metal consisting of 2024-T3 Aluminum plate bonded with an Araldite adhesive using the finite element method to predict damage of the metal in tensile and compressive load under the effect of geometric parameters such as the length of the overlap and the geometric shape of the two plates according to the overlap length. The numerical analysis is performed by the ABAQUS calculation code. The adhesive was modeled by an element of the CZM cohesive zone. the adhesive will be submitted in mixed mode given the non-linearity of the two applied load. the calculation of the failure load will be determined according to the different parameters mentioned above. It is well demonstrated that the type of loading and the parameters taken into consideration condition the strength of the structure. The effect of these different parameters on the strength of the adhesive joint is presented as results by failure load curves.
\end{abstract}

KEYwORDS. Simple lap joint; CZM (Cohesive Zone Modeling); VCCT (Virtual Crack Closure Technique); XFEM (Extended Finite Element Modeling); Tapered plates.

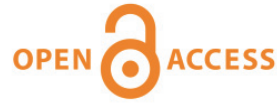

Citation: Benamar, B., Mokhtari, M., Madani, K., Banzaama, H., Using a cohesive zone modeling to predict the compressive and tensile behavior on the failure load of single lap bonded joint, Frattura ed Integrità Strutturale, 50 (2019) 112-125.

Received: 15.06 .2019

Accepted: 30.07 .2019

Published: 01.10.2019

Copyright: (C) 2019 This is an open access article under the terms of the CC-BY 4.0, which permits unrestricted use, distribution, and reproduction in any medium, provided the original author and source are credited. 


\section{INTRODUCTION}

A dhesive bonding is frequently used to manufacture complex-shaped structures and in the several fields of engineering; easy manufacturing and possibility to joint different materials [1]. However, the problem of the single lap joints is the concentrated stress at the edges. This concentration is usually due to the misalignment of the two applied forces. Many ideas have been proposed to reduce the stresses that occur at the end of the overlap. These ideas can be grouped into two categories: fracture parameter of adhesive and or geometric. Groth [2] used the finite element method for predicting breakage in single-cover joints with a spit net.

A large number of predictive techniques is available for bonded joints, either analytical or numerical. Da Silva et al. [3] provide extensive reviews of these methods for analytical methods and X. He [4] for finite element based techniques. Analytical methods are easy to use, but they usually consider simplification assumptions [5]. For complex geometries and elaborate material models, a finite element analysis is preferable to obtain the stress distribution. Fracture mechanics based methods use the fracture toughness of materials as the leading parameter for fracture assessment [6]. Kaye and Heller [7] developed an optimal design of free form bonded and double lap joints, with the aim of achieving reduced peel stresses on the bond line region.

Several parameters determine the quality of a bonded assembly. The strength of the adhesive and the elements to be assembled (brittle or ductile, strong or weak), as well as, the geometry of the joint and the assembled elements. We find the geometric shape of the single lap joint is the most studied in the behavior of assemblies. We find the experimental and numerical comparison work of Barbosa et al. [8] who conducted a study on the effect of lap length, in which they concluded that while tronger and more brittle adhesives are recommended for joint geometries. Banea et al. [9] also experimentally and numerically studied the strengths of joint adhesion. They concluded that failure is dominated by global adhesive yielding and the geometry influence. Luca Sorrentino et al. [10] have also studied the single-lap joint where they demonstrated the effect of surface treatments on the strength of assemblies. Other works such as Costanzo [11] and Banea et al. [12], include the thermal effect on the strength of the adhesive joints.

The effect of the length and depth of a parallel slot on the stress distribution at the mid-bond line and in the adherend was investigated by Yan et al. [13] using the elastic finite element method. In the study of Gültekin et al. [14], mechanical properties of different single lap joint configurations with different adherend width values subjected to tensile loading were investigated experimentally and numerically. In the work of Pinto et al. [15], the Cohesive Zone Models (CZM) are widely used in delaminate on analysis. They not need an pre-existing of crack like (VCCT) Virtual Crack Closure Technique [16, 17]. Many different cohesive element (CZM) formulations have been proposed [18, 19]. However, two main difficulties concerning cohesive elements robustness and their application to large-scale structures still exist.

Firstly, fine meshes are required to appropriate model, which leads to high, and sometimes unaffordable, computational requirements. Secondly, recent findings indicate that the mixed-mode crack propagation predicted by cohesive elements might be unreliable because of an improper estimation of the energy dissipated during the fracture process. The current paper addresses this last difficulty. Other technique implementation in ABAQUS® used without meshing again like the extended finite element modeling (XFEM) [20]. It has used also by Campilho et al. [21] for strength prediction of single and double-lap joints.

The objective of this study is to evaluate by numerical simulation the effect of cohesive stiffness, cohesive strength and fracture energy of the adhesive in order to see their effect on the value of the failure load of the assembly type Aluminum / Aluminum under a compressive and tensile behavior. Four overlap lengths and geometrical parameters modification named tapered have been selected, in order to see also their effect on the failure load of the joint. We also put into consideration the effect of the percentile variation of mode I and mode II on the value of the failure load of the assembly, analyzing the numerical results show that the failure load increases as the adhesive have high strength especially in mode II.

\section{COHESIVE INTERFACES AND INPUT PARAMETER}

7 he separation path using the CZM is entirely in the cohesive zone. The model is a linear tensile-separation law as represented in Fig. 1, defined by a surface of nodes in a mesh without interaction between the surfaces.

1 This technique of selecting the interface with failure parameters is quite different from those already used before for similar studies. It consists of drawing the complete assembled system in a single geometry, no assembly between the different elements. Next, the orphan mesh existing in the ABAQUS calculation code is chosen and the mesh elements are 
subsequently selected in the common plane between the plates, introducing the parameters of rupture of the adhesive. During loading, plate separation occurs when the failure conditions are satisfied.

The cohesive law initially contains a linear regime up to a stress threshold that initiates a softening as the surfaces move away from each other until a separation translated by a null rigidity [22]. The stiffness parameter inputs ( $\mathrm{K}_{\mathrm{nn}}, \mathrm{K}_{\mathrm{ss}}$ and $\left.\mathrm{K}_{\mathrm{tt}}\right)$ required by ABAQUS® are the module of the cohesive $(E, G)$ material divided by its thickness [23].

When $\mathrm{K}_{\mathrm{nn}}=$ Young's modulus / thickness of adhesive layer in normal direction; $\mathrm{K}_{\mathrm{ss}}$ = Shear's modulus / thickness of adhesive layer in tangential direction $1 ; \mathrm{K}_{\mathrm{tt}}=$ Shear's modulus / thickness of adhesive layer in tangential direction 2 . A linear constitutive relationship between stresses $(\sigma)$ and relative displacements $(\delta)$ is established (Fig. 1).

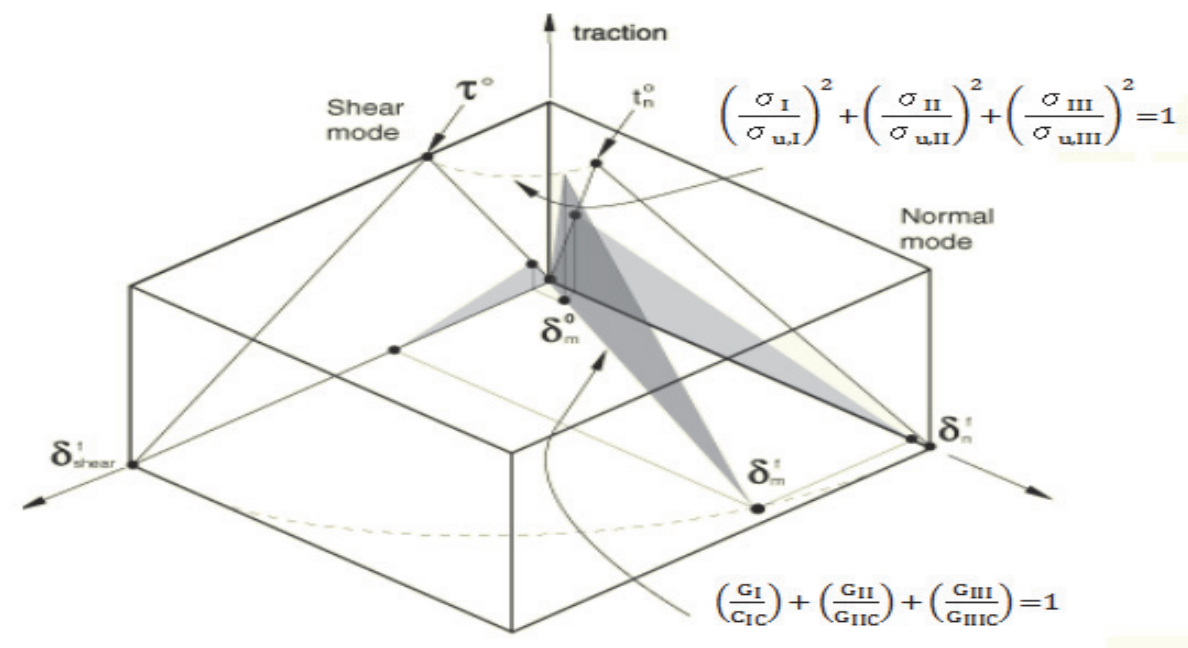

Figure 1: The linear softening law for mixed-mode cohesive damage models.

The model requires the knowledge of the local strengths $\left(\sigma_{\mathrm{u}, \mathrm{i}}, \mathrm{i}=\mathrm{I}, \mathrm{II}, \mathrm{III}\right)$ and of the critical strain energy release rates $\left(\mathrm{G}_{\mathrm{IC}}\right)$. Damage onset is predicted using the following quadratic stress criterion:

$$
\begin{aligned}
\left(\frac{\sigma_{I}}{\sigma_{u I}}\right)^{2}+\left(\frac{\sigma_{I I}}{\sigma_{u I I}}\right)^{2}+\left(\frac{\sigma_{I I I}}{\sigma_{u I I I}}\right)^{2} & =1 \text { if } \sigma_{1} \geq 0 \\
& =0 \text { if } \sigma_{1}<0
\end{aligned}
$$

Where $\sigma_{\mathrm{i}}(\mathrm{i}=\mathrm{I}, \mathrm{II})$ represent the stresses at a given integration point of the interface finite element in each mode. Mode I represents the local opening mode and mode II, III the shear mode at the interface. Crack propagation was simulated by the linear energetic criterion.

$$
\left(\frac{G_{I}}{G_{I C}}\right)+\left(\frac{G_{I I}}{G_{I I C}}\right)+\left(\frac{G_{I I I}}{G_{I I C}}\right)=1
$$

The area under the minor triangle of Fig.1 represents the energy released in each mode, while the bigger triangle area corresponds to the respective critical fracture energy. When Eqn. (2) is satisfied damage propagation occurs and stresses are completely released, with the exception of normal compressive ones [24]. This energy is based on the cohesive damage evolution and it is defined using the Benzeggagh-Kenane criterion [25], with a linear softening law. Fracture energies of $G_{I}=0.3 \mathrm{~N} / \mathrm{mm}$ and $G_{I I}=0.6 \mathrm{~N} / \mathrm{mm}$ are used for normal (Mode I) and shear (Mode II and Mode III) cohesive failures respectively as used by Campilho et al. [26]. The introduced parameters in the calculation code Abaqus are:

\footnotetext{
** MATERIALS

$* *$
}

$*$ Material, name $=$ Cohesive

$*$ Damage Initiation, criterion $=$ QUADS 
40, 24.1, 24.1

$*$ Damage Evolution, type $=$ ENERGY, mixed mode behavior $=$ POWER LAW, power $=2.284$

0.3, 0.6, 0.6

*Damage Stabilization

1e-05

10000. 10000., 10000 .

*Elastic, type $=$ TRACTION

\section{ANALYSIS}

he present study consists in a three-dimensional numerical analysis of tensile and compressive loaded (Fig. 2) with different overlap length in the first, then with geometrical modification in the second. A non-linear material and geometrical analysis was performed, using plane strain rectangular 8-node and triangular 6-node finite elements. Fig. 5 shows a detail of the mesh used at the assembly bond edge. In tensile behavior, the restraining and loading condition consists on clapping of the joint at one edge and applying a vertical restraint and tensile displacement at the opposite edge. The same thing in the compressive behavior but we restraint vertically all length except overlap region the both of the edge in order to favorite the separation, and the tensile replaced by the compressive displace.

The choice of our geometric model in three dimensions, in single and double overlap with composite plates is standardized Mokhtari [27, 28]. See also the works of Benchiha [29] who carried out a study on the influence of defects and the work of Bezzerrouki [30], who has carried out several studies in this line of research. The assembled plates are three-dimensional, except for the two-dimensional joint adhesive designed as an interface. The third dimension (the thickness) is geometrically zero; it is introduced in the stiffness properties (Knn, Kss, Ktt). In this study, the joint adhesive was simulated as an interface. This modality allowed us to evaluate the release force under different parameters, such as adhesive, geometry and mechanical behavior.

a)

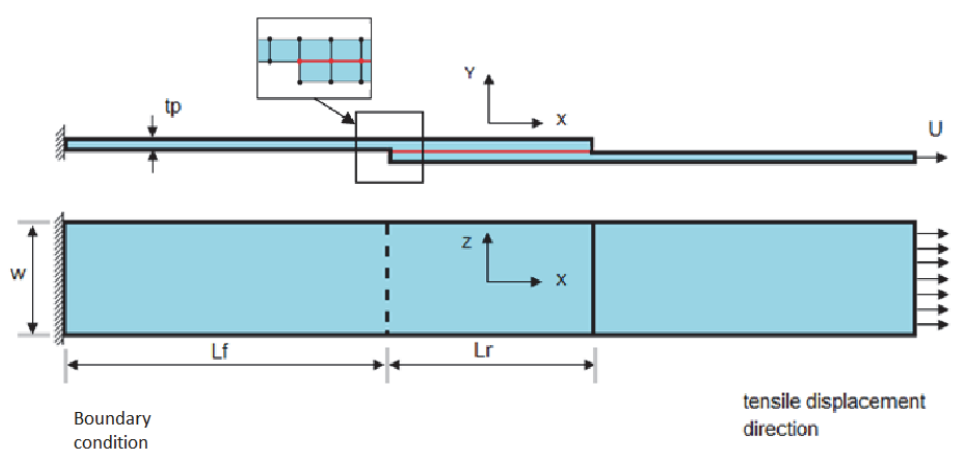

b)

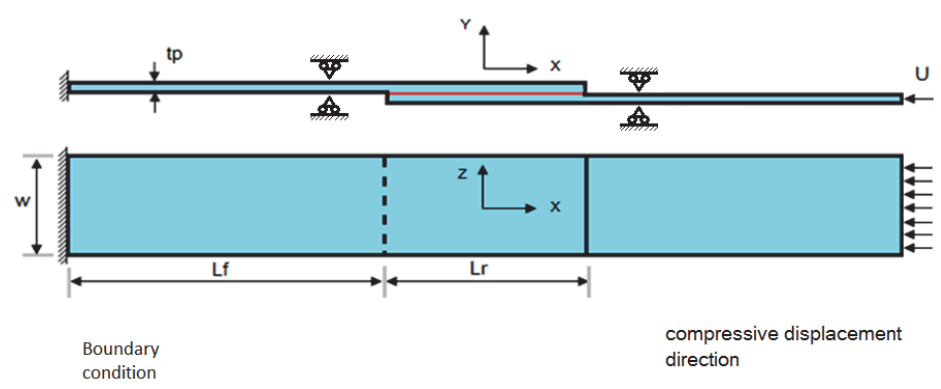

Figure 2: Single lap bonded joint geometry. a) Tensile behaviour ; b) Compressive behaviour.

The boundary conditions are not identical for both the tensile and shear behaviors. For the tensile behavior, it is easy to provoke the debonding with a small bending of the plates, so that they align in the same axis of traction where the adhesive is solicited in mixed mode. On the other hand, it is difficult to favor or provoke the detachment in compression behavior. Since the completely assembled system is free according to the normal, this results in large deformations in 
flexion and without detachment, hence the introduction of boundary conditions in the near vicinity of the overlap, where the adhesive is solicited purely in shear mode.

\begin{tabular}{lccc}
\hline Thickness of the lower and upper adherend & Tp & 2 & $\mathrm{Mm}$ \\
Free length of adherend & Lf & 60 & $\mathrm{Mm}$ \\
Overlap length & W & 15 & $\mathrm{Mm}$ \\
Applied tensile (compression) displacement & $\mathrm{U}$ & 2 & $\mathrm{Mm}$ \\
\hline
\end{tabular}

Table 1: Geometrical properties of single lap bonded.

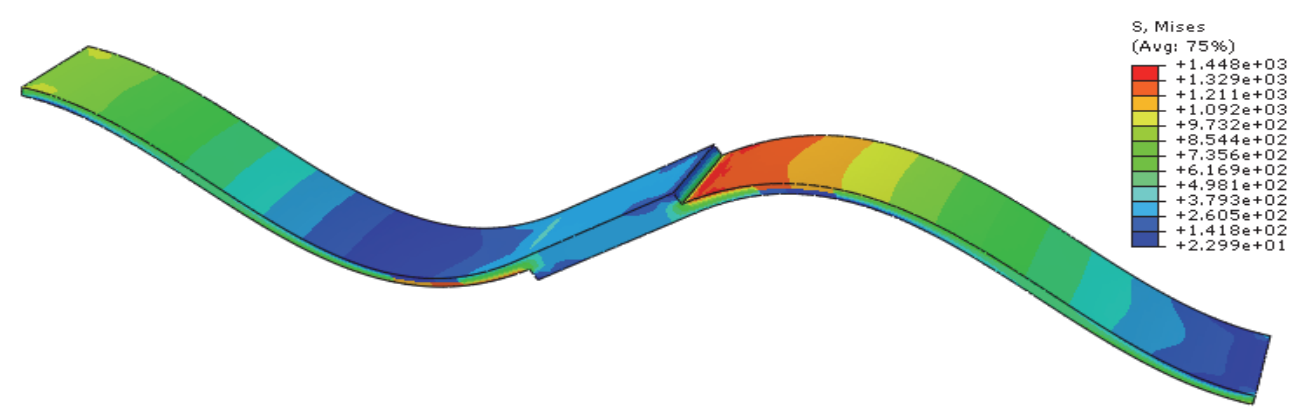

Figure 3: Representation of bonded systems in compression behavior without the conditions add.

Any interaction was introduced between bonded surfaces. The adhesive was modeled as an interface (zero thickness) with $\mathrm{COH} 3 \mathrm{D} 8$ type elements and a number of more than 800 elements depending on the overlap length. Debonding was simulated in the finite element model by keeping the same nodes on both adjacent faces of the overlap area. It is necessary to have an appropriate number of mesh elements in the overlapping region on which the damage properties are conditioned. In other words, when the number of nodes increases or decreases, there will be no convergence and subsequently damage (detachment).
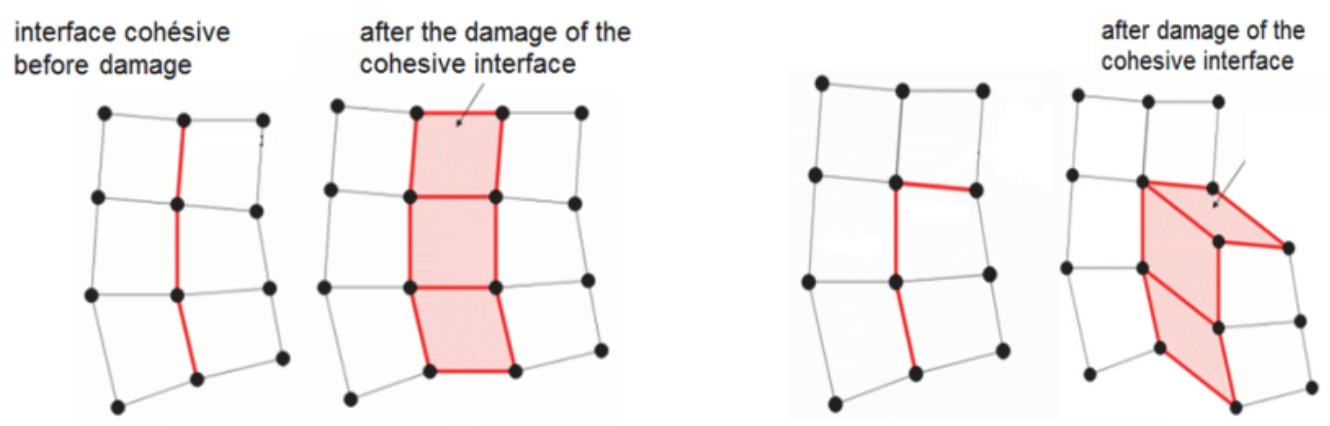

Figure 4: Separation presentation of a cohesive interface.

The mesh in the assembly of all study structures is constructed by essentially identical elements in their sizes at the overlapping levels, as shown in the present figure.

Interface finite elements were used to simulate crack onset and growth, as well as to obtain damage in the adhesive layers. Aluminum adherends, whose mechanical properties are presented in Tab. 2, were used. Tab. 3 shows the strength and failure parameters of the adhesive (Araldite 420). These parameters are obtained by the experimental tests in mode I and in mode II realized by Campilho [26]. These properties were obtained experimentally in [24]. The dimensions of the geometries are presented in Fig. 2. The location of the interface finite elements is shown in Figs. 2 and 5. These elements were placed between the parents of Aluminum adherends and these adherends were modeled as elastic-plastic solids with an approximate curve to the real $(\sigma-\varepsilon)$ curve of Aluminum (Fig. 6). 


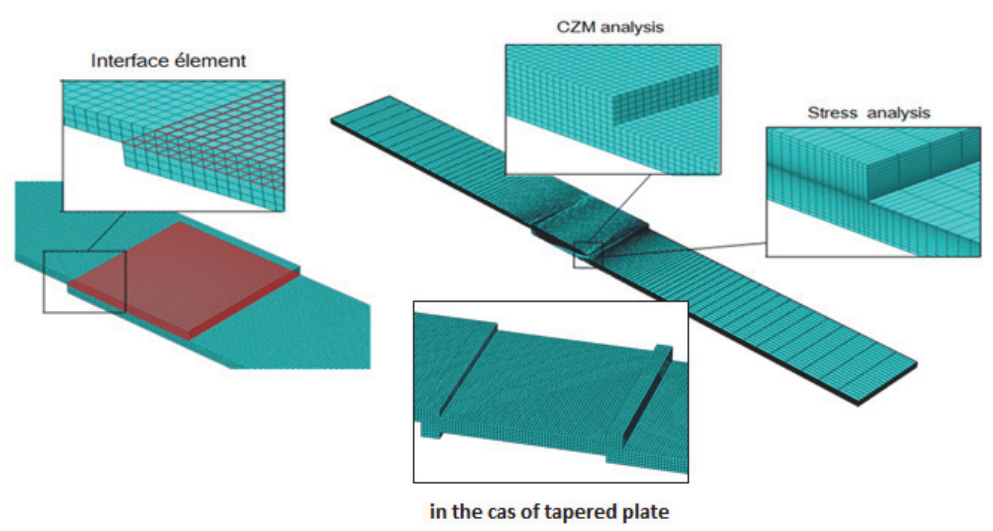

Figure 5: Detail of the mesh and interface element.

\begin{tabular}{lccc}
\hline Young's modulus & $\mathrm{E}$ & 68960 & $\mathrm{MPa}$ \\
Poisson's ratio & $\nu$ & 0.3 & \\
Elastic limit stress & $\sigma_{\mathrm{e}}$ & 220 & $\mathrm{MPa}$ \\
\hline
\end{tabular}

Table 2: Mechanical properties of the adherend used [1]

\begin{tabular}{llcc}
\hline Normal stiffness & $\mathrm{K}_{\mathrm{nn}}$ & $9.25 \times 10^{5}$ & $\mathrm{GN} / \mathrm{m}^{3}$ \\
Shear stiffness & $\mathrm{K}_{\mathrm{ss}}=\mathrm{K}_{\mathrm{tt}}$ & $11.85 \times 10^{5}$ & $\mathrm{GN} / \mathrm{m}^{3}$ \\
Normal strength & $\mathrm{S}_{\mathrm{nn}}$ & 40 & $\mathrm{MPa}$ \\
Shear strength & $\mathrm{S}_{\mathrm{ss}}=\mathrm{S}_{\mathrm{tt}}$ & 24.1 & $\mathrm{MPa}$ \\
Mode I fracture energy & $\mathrm{G}_{\mathrm{I}}$ & 0.3 & $\mathrm{~N} / \mathrm{mm}$ \\
Mode II fracture energy & $\mathrm{G}_{\mathrm{II}}=\mathrm{G}_{\mathrm{III}}$ & 0.6 & $\mathrm{~N} / \mathrm{mm}$ \\
\hline
\end{tabular}

Table 3: Elastic, strength and fracture properties of the adhesive used [26].

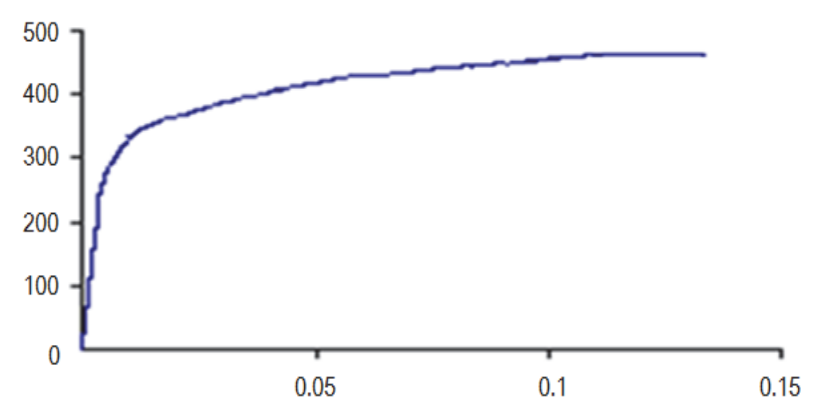

Figure 6: Experimental stress-strain curve of the Aluminum 2024T3 [31].

The behavior of the aluminum plates used in this study is elastic-plastic. The properties introduced in the calculation code for the elastic part are mentioned in Tab. 2. Whereas for the plastic part, they are drawn directly from the curve of Fig. 6 [31].

In the assembly, the plates solicit the joint adhesive to complex behaviors at different levels. It is therefore important to take notes and analyze the lamination caused by the axial loads on the assembled system just before detachment. 
Equivalent stress measurements of Von Misses were taken to identify the plasticization following the exceeding of the elastic limit.
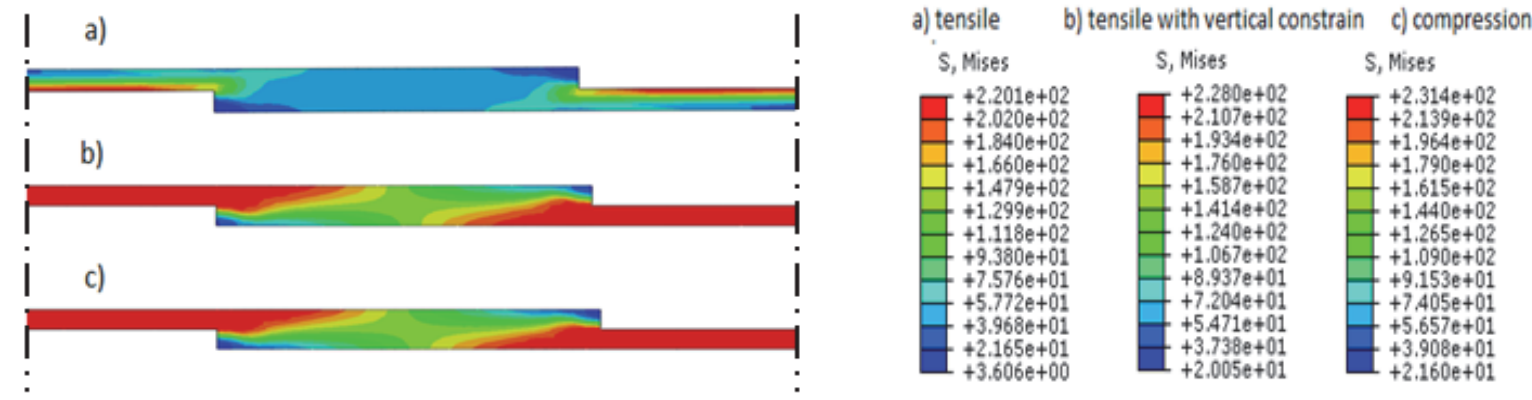

Figure 7: Behavior of the plates before separation.

For the free tensile behavior, plasticization stresses are observed at very low levels which are localized in the bending zones and in order to have the alignment of the plates. But in Figs. b) and c) where the plates are not free plasticization stresses are relatively high at different levels, they are located in the plates to the edges of the cover.

For the notched plates, which explains their advantages, it is the distribution of the loads on the recovery length which will subsequently make the middle of the adhesive active and have more transfer of constraints.
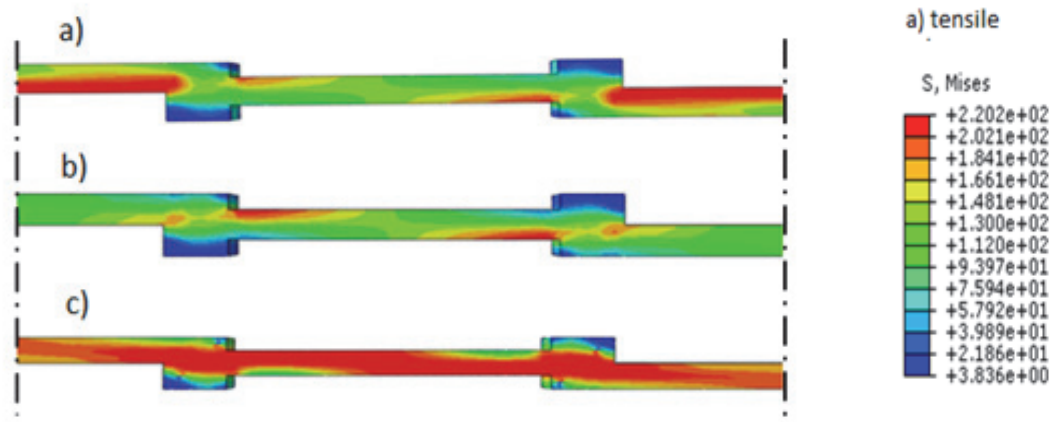

b) tensile with vertical constrain c) compression

Figure 8: Behavior of notched plates before debonding.

Fig. 8 shows the mechanical behavior of notched plates just before debonding. In the case of free or non-free tension, the plastification stresses have very low levels at different concentrations. This is seen in the edges of the lap and at the notch. On the other hand, they reach maximum values at the interface, in the compression behavior, with relatively high levels.

\section{COHESIVE PROPERTIES EFFECTS}

7 he edges of an adhesive joint are always tighter than the rest. From these zones, the separation takes place, the geometric parameters of the assembly and that of the adhesive play a determining role in the system resistance; these are the main variables to be evaluated in this study.

The objective intended to this section is to cancel the property effect in mode to keep the same rapport (GIC / G GIC, $_{\text {, }}$ $\left.\sigma_{\mathrm{UI}} / \sigma_{\mathrm{UII}}\right)$ and to intervener only the effect of values of cohesive properties upon the predicted the failure that occur in assembly with single lap bonded joint configurations, and thus demonstrate the robustness of this type of analysis. The failure loads calculate in this section of analyses show that the compressive and tensile failure of the geometries controlled by the fracture parameters of adhesive. It shows a good agreement between evaluations of parameters; these results were obtained even though the cohesive zone parameters (strength) were estimated, as they were not measured directly.

On the force / displacement curve (Fig. 9), the triangular shape that presents the energy per unit area of the adhesive's ability to withstand the stress, remains the same. For all cases, if the force increases the displacement decreases and vice 
versa. Only that, the conditions (geometry and / or behavior) under which the assembly is subjected influence these values. Indeed, the adhesive joint is more solicited than in its ends, the wider the cover widens, the closer the ends are towards the applied loading and subsequently, the assembly will not have enough time to absorb the energy in the form of displacement and deformation.

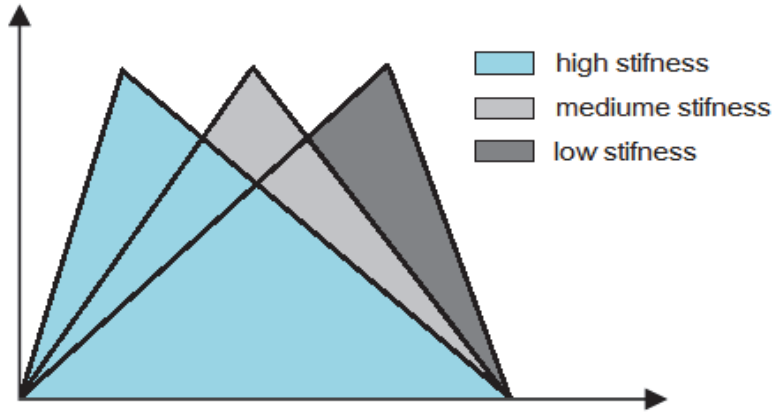

effect of adhésive stifness on the traction-separation law

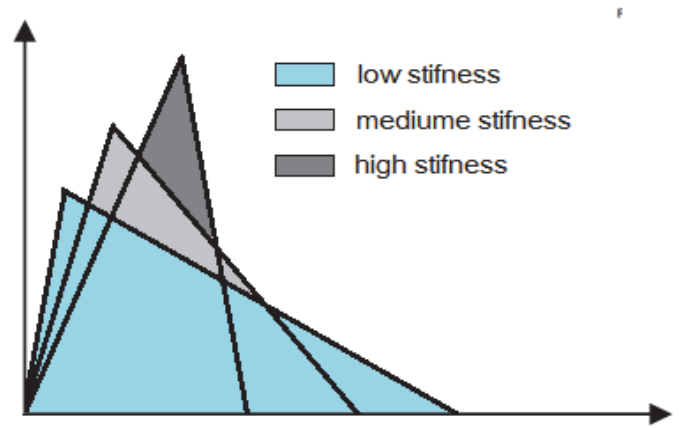

effect of adherend stifness on the traction-separation law

Figure 9: Effect of stiffness adhesive and adherend on the traction-separation law.

\section{Cohesive stiffness effect}

The effect of the cohesive stiffness of the simple lap joint under compressive and tensile stress is analyzed by varying the values of $k_{n n}$ and $k_{t t}$ in the definition of cohesive material; $k_{n n}$ and $k_{t t}$ have both been modified simultaneously to maintain the ratio between them constant. So as to see the effect of the Young's modulus and shear modulus (which are two parameters related to successive cohesive materials; $\mathrm{knn}$ and $\mathrm{ktt}$ ) on the breaking load. In parallel, the breaking energy is kept constant at the base values $\left(G_{I}=300 \mathrm{~J} / \mathrm{m}^{2}, G_{I I}=600 \mathrm{~J} / \mathrm{m}^{2}\right)$ as well as the cohesion force in the base values $\left(\mathrm{S}_{\mathrm{nn}}=40 \mathrm{MPa}, \mathrm{S}_{\mathrm{tt}}=24.1 \mathrm{MPa}\right)$. The variation in compressive and tensile strength of the sample with cohesive rigidity is shown in Fig. 10. The effect of the stiffness of the cohesive zone on tensile and compressive strength is studied.

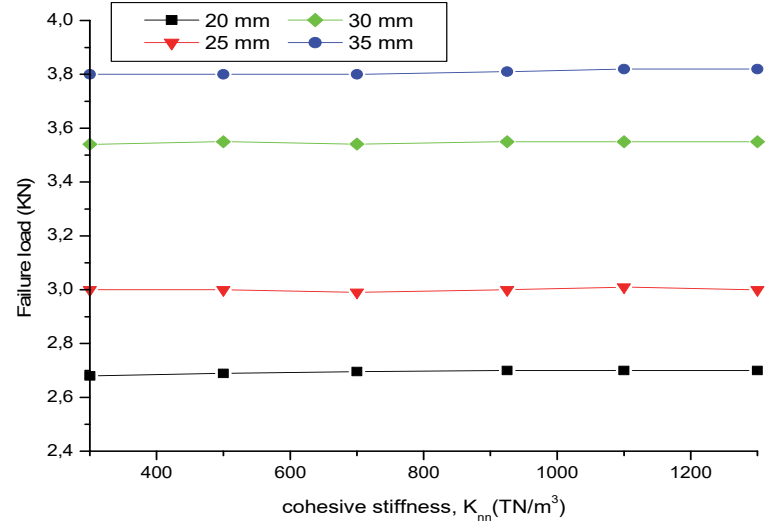

a)

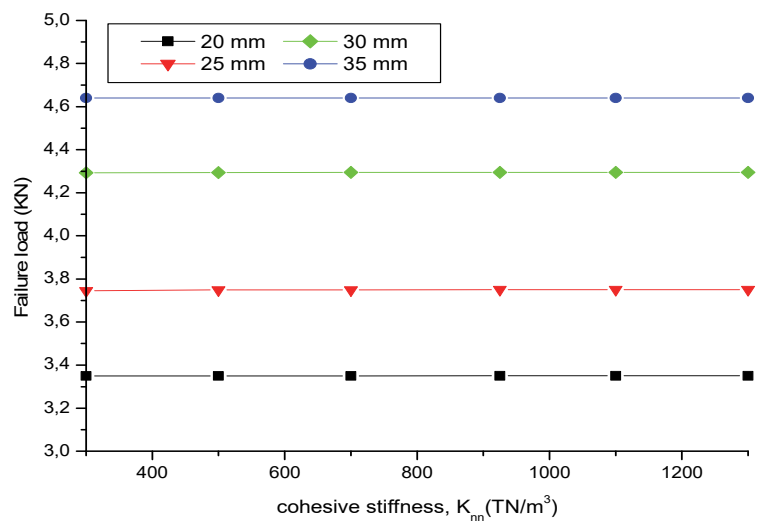

b)

Figure 10: Variation of a) Tensile failure load and b) Compressive failure load as function of cohesive stiffness and overlap length.

For the four selected overlapping lengths, it can be seen that as the length increases, the bonding surface increases and therefore the cohesive layer behaves as a linear elastic material with high load resistance, resulting in a considerable increase in the value of the final tensile strength. By increasing the cohesive stiffness, the value of the breaking strength changes slightly. Even when the joint is subjected to tension or compression, the value of the failure load changes so that it will be higher in compression. Indeed, the cohesive rigid layer does not support large longitudinal displacements and under compressive stress, the joint peels off in mode II. 


\section{Fracture energy effect}

The results of the damage analyses provided for in the adhesive joint are based on the geometric conditions of the bonded system, the properties of the two plates and their dimensions and the damage properties of the adhesive.

Recent studies have shown that bonded assemblies have significantly different and variable failure energies [32]. Therefore, it is appropriate to examine whether variation in this parameter will affect failure mechanisms under tensile and compressive stress.

Our analysis is based on the variation of the $G_{I}$ and $G_{I I}$ fracture energies while ensuring the $G_{I} / G_{I I}$ ratio is maintained constant. On the other hand, the different parameters concerning the modeling of the cohesive zone are kept constant and fixed at the reference values indicated in Tab. 2. Fig. 11 shows the effect of the fracture energy on the maximal fracture load under tensile and compressive solicitation.

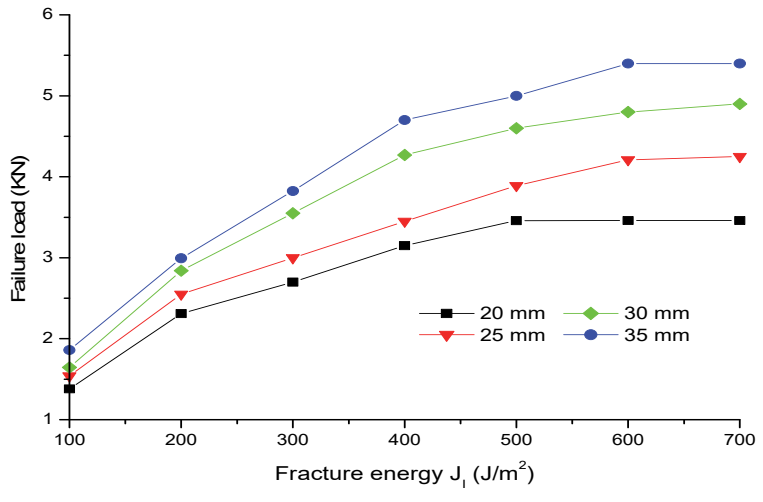

a)

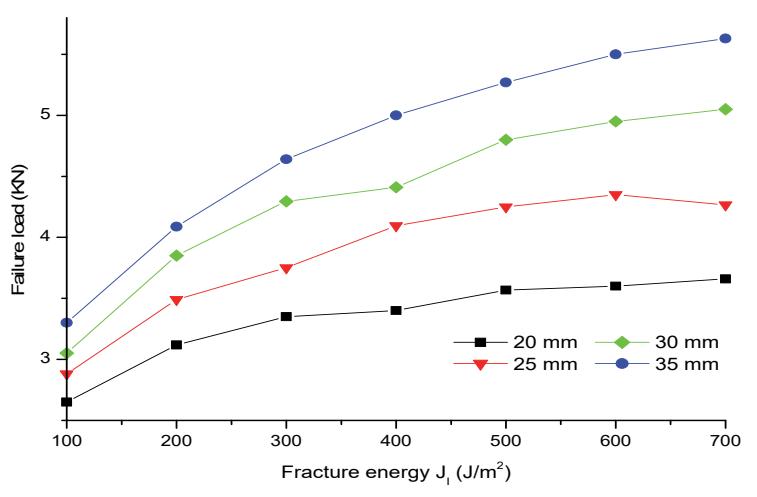

b)

Figure 11: a) Compressive and b) Tensile failure load as function of the fracture energy and overlap length.

It can be seen from Fig. 11 that the failure load values are high in the case of compressive stress because the adhesive are more resistant to shear than to tension. For small values of the failure energy of the adhesive, the overlap length has little influence on failure load, the difference in value is more noticeable in the case of compressive stress than in tension. By increasing the breaking energy value, the adhesive will continue to resist efforts to transmit the load to the plates thus giving high strength. Compared to other parameters, such as, normal and tangential resistances $\mathrm{S}_{\mathrm{nn}}, \mathrm{S}_{\mathrm{tt}}$ and $\mathrm{S}_{\mathrm{ss}}$, the separation energies of the adhesive $G_{I}, G_{I I}$ and $G_{I I I}$ play the most important role on the strength of the adhesive and therefore on the value of the breaking force as shown in Fig. 11.

The failure of this type of assembly is very sensitive to low value failure energy, especially for short overlap lengths. But in contrast to high values of failure energy. However, as the overlap length increases, the value of the failure load increases resulting in high strength of the assembly. It is clearly noted that the values of the breaking force as a function of the length of the overlap under compressive stress are presented with a high level only for tensile stress because the loaded compression joint behaves in pure shear.

\section{Cohesive zone strength effect}

The effect of cohesive zone strength of the system under compressive and tensile strength is investigated by varying the values of $S_{n n}$ and $S_{t t}$, in the cohesive material definition, that means both $S_{n n}$ and $S_{t t}$ were varied simultaneously to keep the ratio between them constant. The fracture energy is held constant at the baseline values $\left(G_{I}=300 \mathrm{~J} / \mathrm{m}^{2}, G_{I I}=600 \mathrm{~J} / \mathrm{m}^{2}\right)$. The variation of compressive strength of the specimen with cohesive strength is shown in Fig. 12, for the two solicitations of compressive and tensile. Adhesive by its nature can be presented under different behavior; ductile or rigid according to its strength properties.

We notice that the value of the failure load increases with the increase in the tensile strength of the adhesive. Under tensile stress the value of the failure load reaches a stable value once the value of the tensile strength exceeds $40 \mathrm{MPa}$, whereas in compression, the value of the failure load continues to increase by increasing the value of the tensile strength. On the other hand, by increasing the overlap length, the value of the failure load increases considerably to give a high resistance to the joint. If the adhesive is resistant $\left(\mathrm{S}_{\mathrm{nn}}\right.$ high) it will support more the applied load, it will have less longitudinal displacement and therefore an increase in the failure load. 
It is also shown that all values of the failure load in compressive load are represented with a high level than in tensile load, because, the joint on the compressive load works more in pure shear.

It is also shown that all values of the breaking force in compressive stress are represented with a high level than in tensile stress, because the joint on the compressive load works more in pure shear.

In the case of tensile loading, the ultimate stress effect disappears once the value $\mathrm{S}_{\mathrm{nn}}>40 \mathrm{MPa}$ is exceeded. Unlike in the case of compressive stress where the joint strength can be high (Fig. 12 b).

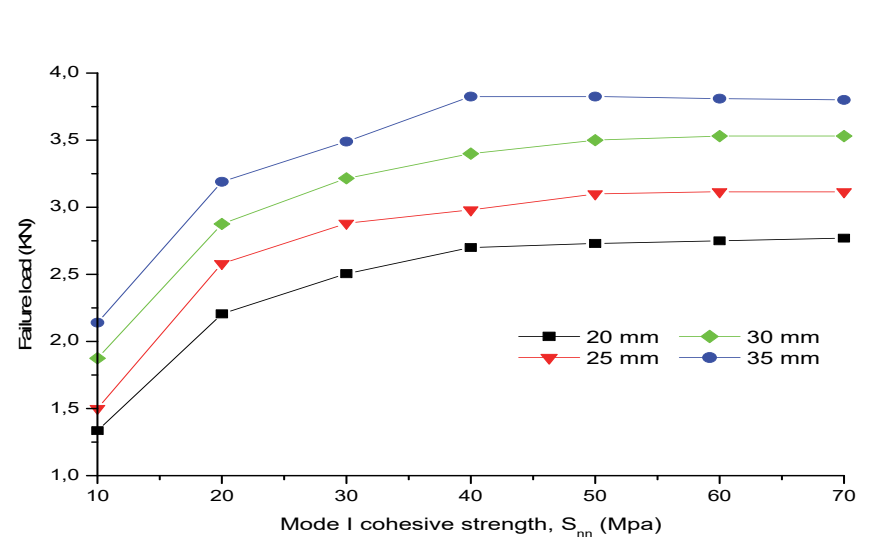

a)

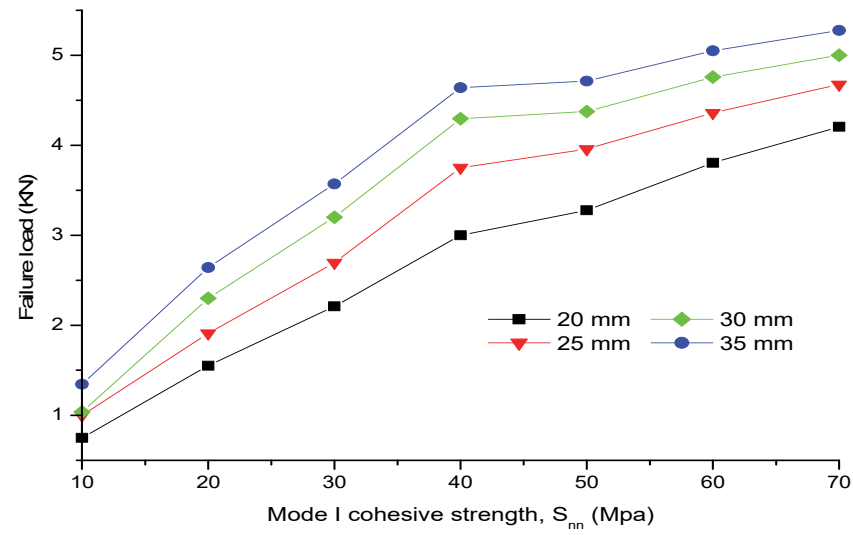

b)

Figure 12: a) Compressive and b) Tensile failure load as function of the cohesive strength and overlap length.

\section{Effect of tapered geometry on the failure load}

In single lap bonded joints, the adhesive works more at the levels of these extremities, however the covering medium remains almost inactive, hence the idea of introducing a so-called tapered geometric modification in order to make it work more easily in all its surface. This part of the study gives the advantage of even the external effect (of the plates) on the resistance of the assembly where the effect of the thickness and length of notch on the results has been evaluated (failure load) for the two behaviors: traction and compression.

The percentages by contribution to e $=0.75 \mathrm{~mm}$ and $1=22.5 \mathrm{~mm}$ where the length of recovery was fixed at $25 \mathrm{~mm}$, as presented in the table and the figure below. The dimensional parameters of the notch are taken at a time and separately to better identify their effects.

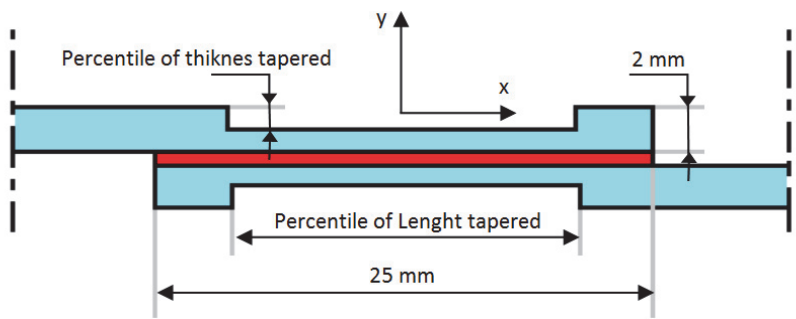

Figure 13: Tapered geometry modified of single lap bonded joint.

\begin{tabular}{lcccccccc}
\hline Percentile evaluation & $(\mathrm{c} /)^{2}$ & -30 & -20 & -10 & 0 & 10 & 20 & 30 \\
Thickness tapered & $(\mathrm{mm})$ & 0.5 & 0.58 & 0.67 & 0.75 & 0.84 & 0.92 & 1 \\
Length tapered & $(\mathrm{mm})$ & 10 & 14.18 & 18.34 & 22.5 & 26.67 & 30.83 & 35 \\
\hline
\end{tabular}

Table 4: Tapered geometry dimensions of adherends used. 
In Fig. 14, the common effect on the results shows that the presence of the notch in the plates weakened their rigidity and subsequently more elongation in the plates that come from the separation energy is absorbed. The rigidity of the assembled plates is responsible for the detachment force.

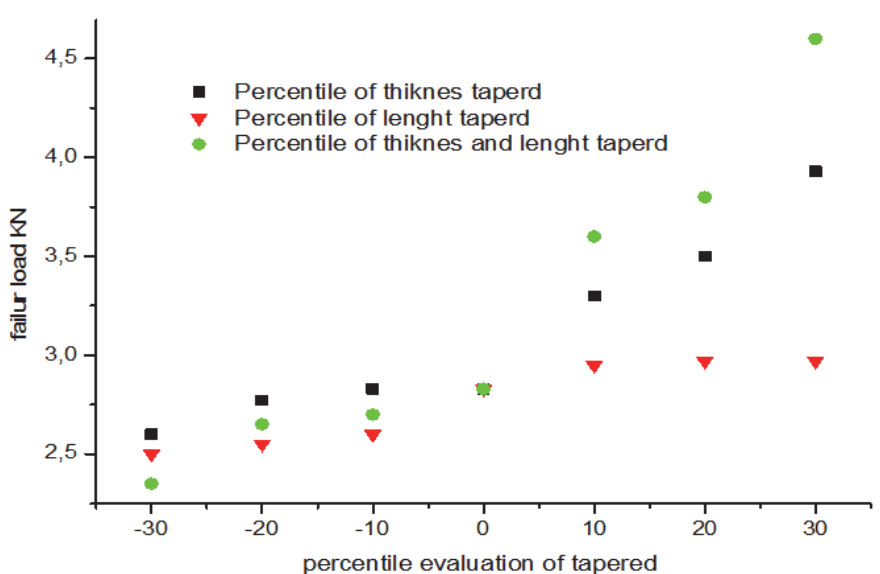

a)

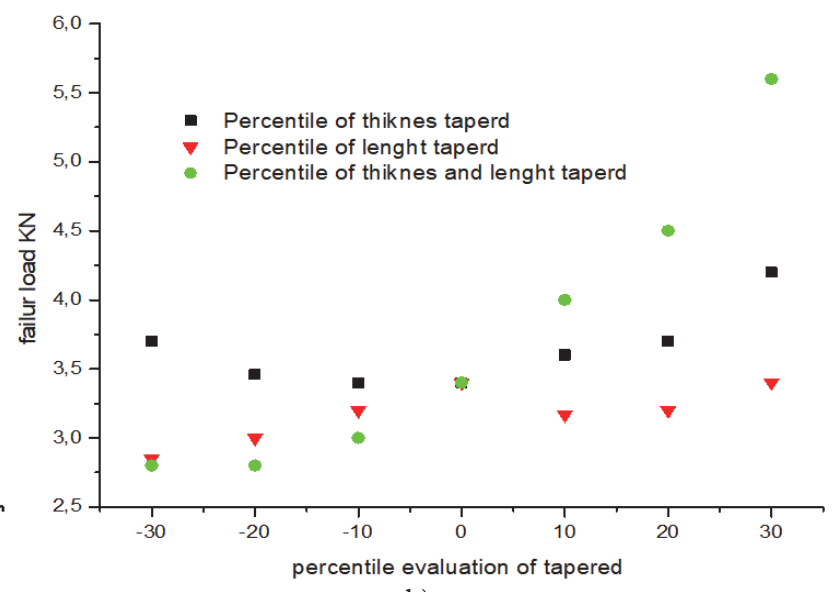

b)

Figure 14: a) Tensile and b) Compressive failure load as function of the tapered parameters (overlap length $=25 \mathrm{~mm}$ ).

\section{SENSITIVITY ANALYSES}

$\Lambda$ dditional to the precedent analyses and considering, the two plate geometries at the overlap level, the sensitivity analyses were performed on the cohesive parameters, which play a significant role in the failure process and are not measured by specific experimental tests [33]. A study was conducted. The influence of fracture properties of the adhesive mode I ( $\left.\mathrm{G}_{\mathrm{IC}}, \sigma_{\mathrm{UI}}\right)$, mode II $\left(\mathrm{G}_{\mathrm{IIC}}, \sigma_{\mathrm{UII}}\right)$ and overall $\left(\mathrm{G}_{\mathrm{IC}}, \sigma_{\mathrm{UI}}, \mathrm{G}_{\mathrm{IIC}}, \sigma_{\mathrm{UII}}\right)$ properties on failure load was also analyzed. From $-50 \%$ to $+50 \%$ we ranging the values of the initial ones considered in this analysis Tab. 3 were considered. Fig. 15 presents the failure load under tensile and compressive behavior as function of the cohesive properties. The failure load of the same geometry using the initial properties $\left(\mathrm{F}_{0}\right)$ normalizes these failure loads. Overall, the failure load increases with each group of properties considered in this study. As expected, mode II properties have a higher effect on the failure load; especially the compressive behavior with the boundary condition is primarily loaded in shear.

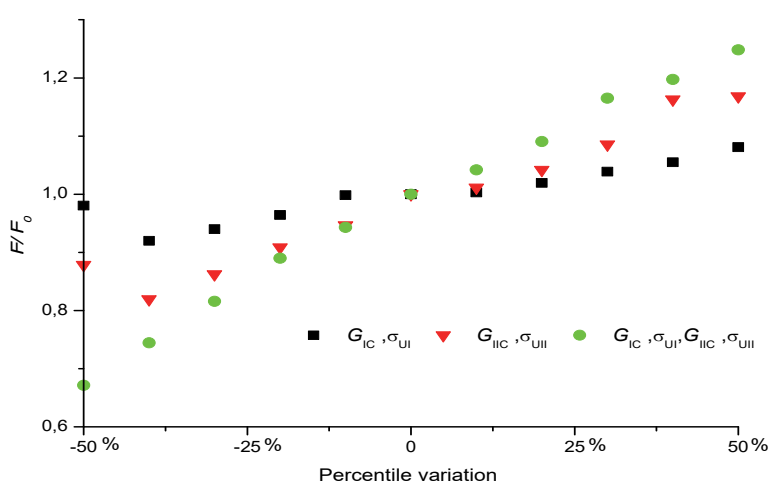

a)

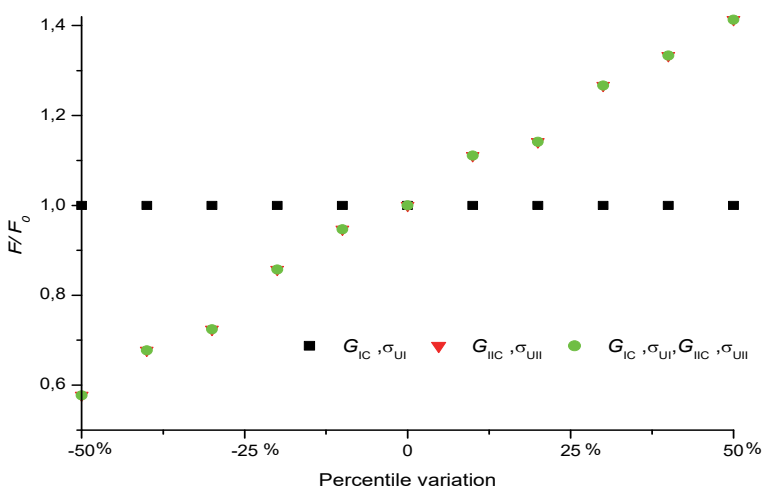

b)

Figure 15: a) Tensile failure load and b) Compressive failure load as function of the cohesive properties $\left(l_{0}=25 \mathrm{~mm}\right)$.

Fig. 16 shows that the failure load is conditioned by boundary condition: Type of load and the restraining. The results obtained show that the fracture properties of the adhesive have a little influence on the failure load for mode I, while it's 
not the case for the mode II; the fracture properties present a major influence, it's explained by the fact that shears stresses leading to failure of adhesive. For very low fracture properties, a slight reduction in the joint strength is observed.

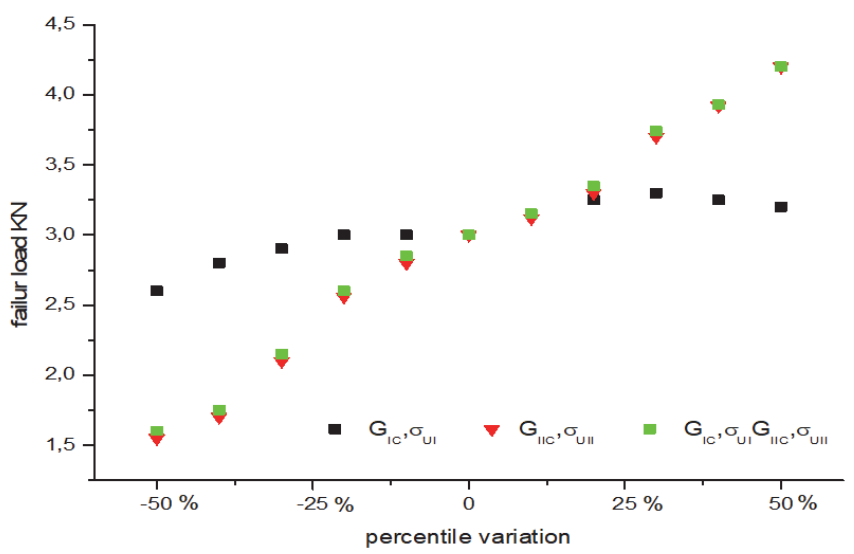

a)

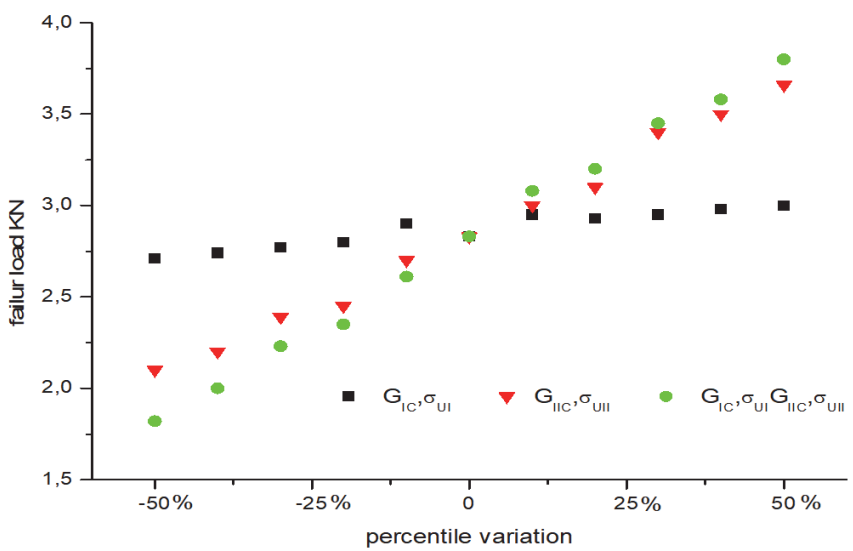

b)

Figure 16: a) Tensile and b) Compressive failure load as function of the cohesive properties (overlap length $=25 \mathrm{~mm}$ ).

The results for the notched plates show that for all the breaking properties of the adhesive, the higher they are, the higher the peel forces are. The percentage variation of the properties in mode I do not have much effect on the force of separation by contribution to the properties in mode II, more particularly in compression. This shows that the overlap assembly is stressed much more in shear than in tension, it depends on the geometrical conditions of the loading and fixing joint in which the assembly is subjected. In this case, the compression release forces are not very important compared to the shear behavior as in the case of non-notched plates.

\section{CONCLUSION}

his study has been focused on numerical simulation based on the Cohesive Zone Modeling method of a single lap joint with different situation such as fracture parameter of adhesive, behavior of assembly and geometric adhered, the following conclusions could be deduced from the obtained results:

- Cohesive Zone Modeling gives the advantage of numerically predicting the release force by evaluating the parameters of adhesive failure, as well as the geometrical conditions and the behavior in which the assembly is subjected. This method also allows numerically to introduce a damaging interface into a solid without performing an assembly.

- The rigidity effect of the interface is negligible except for small values that can destabilize the assembly and give different values of the release force.

- Failure parameters of the adhesive condition the value of the detachment force of the assembly, the higher the ultimate stress and the breaking energy increase, the more the peel force increases.

- The level of the release force depends on the rigidity and geometry of the plates, less deformation and more debonding force.

- The level of the debonding force also depends on loading and / or fixation conditions.

- The variations of the parameters of adhesive rupture by mode I and / or mode II, directly affect the level of resistance, hence the influence of the behavior in tension or in compression.

- All parameters influencing the debonding force remain limited up to the strength of the adhesive joint.

\section{REFERENCES}

[1] Lee, M.J., Cho, T.M., Kim, W.S., Lee, B.C. and Lee, J.J. (2010). Determination of cohesive parameters for a mixedmode cohesive zone model, Int. J. adhes. adhes., 30(5), pp. 322-328. DOI: 10.1016/j.ijadhadh.2009.10.005. 
[2] Groth, H.L. (1988). Stress singularities and fracture at interface corners in bonded joints, Int. J. adhes. adhes., 8(2), pp. 107-113. DOI: 10.1016/0143-7496(88)90031-0.

[3] Da Silva, L.F.M., Das Neves, P.J.C. and Adams, R.D. (2009). Analytical models of adhesively bonded joint, Part 1: Literature survey, Int. J. adhes. adhes. 29(3), pp. 319-330. DOI: 10.1016/J.IJADHADH.2008.06.005.

[4] He X. (2011). A review of finite element analyses of adhesively bonded joints, Int. J. adhes. adhes., 31(4), pp. 248-264. DOI: 10.1016/J.IJADHADH.2011.01.006.

[5] Hart Smith, L.J. (1973). Adhesive bonded single lap joint, NASA CR 112236.

[6] Chai, H. (1988). Shear fracture, Int. J. fract., 37(2), pp. 137-159.

[7] Kaye, R., Heller, M. (2002). Through-thickness shape optimization of bonded repairs and lap joints, Int. J. adhes. adhes., 22 (1), pp. 7-21. DOI: 10.1016/S0143-7496(01)00029-X.

[8] Barbosa, N.G.C., Campilho, R.D.S.G., Silva, F.J.G. and Moreira, R.D.F. (2018). Comparison of different adhesivelybonded joint types for mechanical structures, Appl. Adhes. Sci., 6(15). DOI: 10.1186/s40563-018-0116-1.

[9] Banea, M.D., Rosioara, M., Carbas, R.J.C. and da Silva, L.F.M. (2018). Multi-material adhesive joints for automotive industry, Composites Part B: Engineering, 151(15), pp. 71-77. DOI: 10.1016/J.COMPOSITESB.2018.06.009.

[10] Sorrentino, L., Polini, W., Bellini, C., and Parodo, G. (2018). Surface treatment of CFRP: Influence on single lap joint performances, Int. J. adhes. adhes., 85, pp. 225-233. DOI: 10.1016/j.ijadhadh.2018.06.008.

[11] Bellini, C., Parodo, G., Sorrentino, L. (2019). Effect of operating temperature on aged single lap bonded joints, Defence Technology. DOI: 10.1016/j.dt.2019.05.015.

[12] Banea, M.D., da Silva, L.F.M., Carbas, R.J.C. and de Barros, S. (2017). Debonding on command of multi- material adhesive joints, Journal of Adhesion, 93(10), pp. 756-770. DOI: 10.1080/00218464.2016.1199963.

[13] Yana, Z.M., Youa, M., Yib, X.S., Zhenga, X.L. and Lia, Z. (2007). A numerical study of parallel slot in adherend on the stress distribution in adhesively bonded aluminum single lap joint, Int. J. adhes. adhes., 27(8), pp. $687-695$. DOI: $10.1016 /$ j.ijadhadh.2007.02.003.

[14] Gültekin, K., Akpinar, S., Özel, A. (2014). The Effect of the Adherend Width on the Strength of Adhesively Bonded Single-Lap Joint: Experimental and Numerical Analysis, Composites Part B: $\quad$ Engineering, 60 pp. $736-745$. DOI: 10.1016/j.compositesb.2014.01.022.

[15] Pinto, A.M.G., Ribeirob, N.F.Q.R., Campilho, R.D.S.G. and Mendesb, I.R. (2014). Effect of adherent recessing on the tensile strength of single lap joints, Journal of Adhesion, 90(8), pp. 649-666. DOI: 10.1080/00218464.2013.766132.

[16] Krueger, R. (2004). The virtual crack closure technique: History, approach, and applications, Appl. Mech. Rev., 57(2), pp. 109-143. DOI: $10.1115 / 1.1595677$.

[17] Tay, T. (2003). Characterization and analysis of delamination fracture in composites: an overview of developments from 1990 to 2001. Appl. Mech. Rev., 56(1), pp. 1-32. DOI:10.1115/1.1504848.

[18] Needleman, A. (1987). A continuum model for void nucleation by inclusion debonding. J. Appl. Mech., 54(3), pp. 2531. DOI: $10.1115 / 1.3173064$.

[19] Jiang, W., Hallett, S.R., Green, B.G. and Wisnom, M.R. (2007). A concise interface constitutive law for analysis of delamination and splitting in composite materials and its application to scaled notched tensile specimens. Int. J. Numer. Methods Eng., 69(9), pp. 1982-1995. DOI: 10.1002/nme.1842.

[20] Mohammadi, S. (2008). Extended finite element method for fracture analyses of structures, Wiley/Blackwell. DOI: $10.1002 / 9780470697795 . c h 7$.

[21] Campilho, R.D.S.G., Banea, M.D., Pinto, A.M.G., da Silva, L.F.M. and de Jesus, A.M.P. (2011). Strength prediction of single and double lap joint by standard and extended finite element modelling, Int. J. adhes. adhes., 31(5), pp. 363372. DOI: 10.1016/j.ijadhadh.2010.09.008.

[22] Turon, A., Davila, C.G., Camanho, P.P. and Costa, J. (2007). An engineering solution for mesh size effects in the simulation of delamination using cohesive zone models. Engineering Fracture Mechanics, 74(10), pp. 1665-1682. DOI: $10.1016 /$ j.engfracmech.2006.08.025

[23] Abaqus Analysis Users’ Manual. Version 6.8. Dassault Systems, 2008.

[24] Campilho, R.D.S.G., Demoura; M.F.S.F. And Domingues, J.J.M.S. (2007). Stress and failure analyses of scarf repaired CFRP laminates using a cohesive damage model, J. Adhesion Sci. Technol., 21(9), pp. 855-870.

DOI: $10.1163 / 156856107781061477$.

[25] Benzeggagh, M.L., Kenane, M. (1996). Measurement of mixed-mode delamination fracture toughness of unidirectional glass/epoxy composites with mixed mode bending apparatus. Compos Sci. Technol., 56(4), pp. 439449. DOI: 10.1016/0266-3538(96)00005-X. 
[26] de Moura, M.F.S.F., Daniaud, R. and Magalhães, A.G. (2006). Simulation of mechanical behaviour of composite bonded joints containing strip defects, Int. J. adhes. adhes., 26, 464-473. DOI:10.1016/j.ijadhadh.2005.06.010.

[27] Mokhtari, M., Madani, K., Benzaama, H. and Malarino, S. (2017). Effects of the composite stacking sequence on the failure load of the single lap bonded joint, Journal of Theoretical and Applied Mechanics, 55(4), pp. $1257-1268$. DOI: $10.15632 /$ jam-pl.55.4.1257.

[28] Mokhtari, M., Madani, K., Belhouari, M., Touzain, S., Feaugas, X. and Ratwani, M. (2013). Effects of composite adherend properties on stresses in double lap bonded joints, Materials and Design, 44, pp. 633-639. DOI: $10.1016 /$ j.matdes.2012.08.001.

[29] Benchiha, A., Madani, K. (2015). Influence of the presence of defects on the stresses shear distribution in the adhesive layer for the single-lap bonded joint, Structural Engineering and Mechanics, 53(5), 1017-1030. DOI: $10.12989 /$ sem.2015.53.5.1017.

[30] Bezzerrouki, M., Madani, K., Sahli, A. and Mallarino, S. (2019). Innovative geometric design improves the resistance of simple metal / metal lap joint, Frattura ed Integrità Strutturale, 13(48), pp. 491-502. DOI: $10.3221 /$ IGF-ESIS.48.47.

[31] Madani, K., Touzain, S., Feaugas, X., Cohendouz, S. and Ratwani, M. (2010). Experimental and numerical study of repair techniques for panels with geometrical discontinuities, Computational Materials Science, 48(1), pp. 83-93. DOI: $10.1016 /$ j.commatsci.2009.12.005.

[32] Mukherjee, A. (1997). Ply drop-off in layered composites-evaluation of design parameters, Computational structural mechanics. Allied Publishers Ltd., pp. 473-82.

[33] Campilho, R.D.S.G., de Moura, M.F.S.F. and Domingues, J.J.M.S. (2008). Using a cohesive damage model to predict the tensile behaviour of CFRP single-strap repairs, International Journal of Solids and Structures, 45(5), pp. 14971512. DOI: $10.1016 /$ j.ijsolstr.2007.10.003. 